\title{
CONTRASTING FORAGING STRATEGIES AND COEXISTENCE OF TWO BEE SPECIES ON A SINGLE RESOURCE ${ }^{1}$
}

\author{
LESLIE K. JOHNSON ${ }^{2}$ \\ Department of Zoology, University of California, Berkeley, California 94720 USA \\ AND \\ STEPHEN P. HubBell2 ${ }^{2}$ \\ Department of Zoology, University of Michigan, Ann Arbor, Michigan 48104 USA
}

\begin{abstract}
The foraging patterns of two eusocial stingless bees, Trigona fuscipennis and Trigona fulviventris, were studied on a population of the shrub, Cassia biflora, in a tropical dry forest in Costa Rica. Trigona fuscipennis, which forages in large groups that monopolize plants, restricted its visits to large, dense clumps of Cassia. Visited plants had significantly more flowers than nonvisited plants. Trigona fulviventris, which forages as individuals or in small groups, visited more widely spaced or isolated plants. In the isolated plants visited by $T$. fulviventris, there was no significant difference in the number of flowers on visited vs. nonvisited plants. In clumps, however, the few plants visited by $T$. fulviventris had significantly fewer flowers than plants not visited. This observation and observations of interspecific aggression suggests that $T$. fulviventris is excluded from the better plants in clumps by $T$. fuscipennis. We believe the observed foraging patterns result from both evolved strategies and displacement due to short-term ecological competition. To explain the results, we hypothesize that two species may stably partition and coexist on a single resource, provided that (1) the resource has a highly variable spatial dispersion pattern, ranging from dense local patches to large regions of thinly spread resource, (2) the thinly spread resource is profitably harvested by only one of the species, (3) the dense patches are controlled by the second species, and (4) the resource is nonmobile such that no mixing of resource occurs between dense and sparse areas. We propose the terms "low- and high-density specialists" to describe such species.
\end{abstract}

Key words: Bees, stingless; coexistence; Costa Rica; density specialization; foraging strategy; insect, social; resource partitioning; Trigona.

\section{INTRODUCTION}

Two species of stingless bees, Trigona fuscipennis Friese and Trigona fulviventris fulviventris Guérin, foraged for several months in $1972-73$ on the pollen of Cassia biflora L., a legume shrub of the tropical dry forest life zone (Holdridge 1967), in the Pacific lowlands of Costa Rica.

We undertook a study to determine how the two species utilized the same food resource and whether competition was occurring. Earlier observations (Johnson 1974) suggested that these two species might employ very different foraging strategies, and could achieve the stable partition of a common food resource, provided that the resource was persistent and had a highly variable pattern of spatial dispersion. Cassia biflora proved to be an excellent food resource for testing this possibility. The Cassia population flowered from late November to late March and exhibited the required variability in pattern of dispersion. Cassia, a very important dry season flowering plant in Guanacaste, was a particularly significant food plant for bees in the drought year

\footnotetext{
${ }^{\text {' }}$ Manuscript received 29 July 1974; accepted 1 March 1975.

" Present address: Department of Zoology, The University of Iowa, Iowa City, Iowa 52242 USA.
}

1972-73 when fewer alternative flowers bloomed (Johnson 1974).

One colony each of Trigona fuscipennis and Trigona fulviventris foraged on the Cassia population. Both bee species are of equivalent size, come from colonies of approximately equivalent numbers of individuals (Johnson 1974), and employ the same method of pollen extraction, namely chewing open the thick-walled anthers (Wille 1963).

\section{Methods}

The study site is located on the Comelco Ranch in Guanacaste Province, Costa Rica (lat. $10^{\circ} 32^{\prime} \mathrm{N}$, long. $85^{\circ} 18^{\prime} \mathrm{W}$ ), about $25 \mathrm{~km} \mathrm{NW}$ of Cañas. The site (Fig. 1) contains a strip of forest-savanna ecotone where Cassia, a second growth species, grows abundantly in patches and as isolated plants.

The study area, $260 \mathrm{~m}$ by $160 \mathrm{~m}$, was gridded with stakes at $20-\mathrm{m}$ intervals. Within these quadrats each Cassia was numbered on a piece of masking tape attached to the stem, and mapped to the nearest $0.5 \mathrm{~m}$. One nest each of Trigona fuscipennis and $T$. fulviventris occurred in the study area; these were mapped. There were two patches of Cassia. One was termed the "near patch" as it was closer to both nests, while the other was termed the "far patch." 


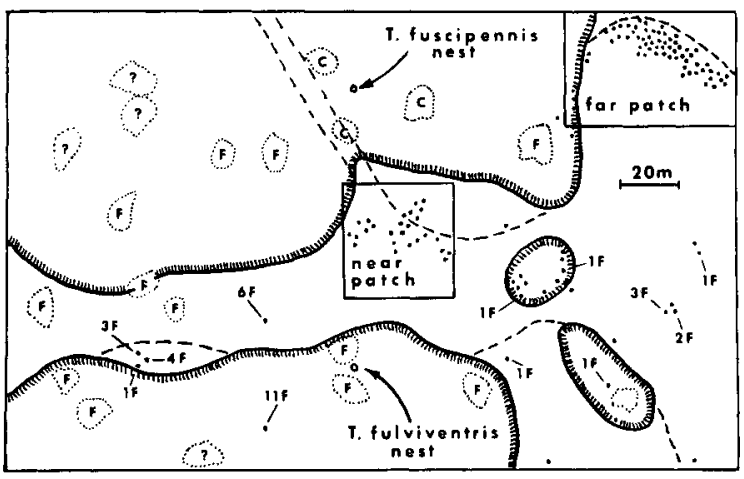

FIG. 1. Map of study site $(260 \mathrm{~m} \times 160 \mathrm{~m})$. Hatched lines mark boundaries of forest, and dotted lines mark edges of brush patches. Dots represent individual Cassia biflora shrubs. Dotted, irregular circles are outlines of the canopies of Calycophyllum candidissimum trees also visited by Trigona fulviventris (F) and $T$. fuscipennis (C). Isolated Cassia shrubs visited by $\mathrm{F}$ or $\mathrm{C}$ are marked with the number of bees present. Near and Far patches are expanded in Figs. 3 and 2, respectively. North is toward top of figure.

Counts of bees and open flowers were made for each plant between 1000 and 1100 on three successive days in December 1972. Plants in the near patch were surveyed on the 17 th, the widely spaced plants on the 18th, and those in the far patch on the 19th. Thirty-six selected plants were rechecked four more times at 3 to 4 -day intervals.

We timed the duration of flower visits and round trip flights for bees individually marked on the thorax with a dot of Testor's paint. The constancy of these bees to particular plants was noted.

We also observed visitation patterns on the simultaneously flowering Calycophyllum candidissimum trees (Rubiaceae). Tree crowns near the savanna strip were observed from the $15-\mathrm{m}$ platform of an elevator truck; tree crowns within the forest were observed through binoculars. The Calycophyllum were also mapped.

\section{RESULTS}

The conviction that all individuals of $T$. fuscipennis and T. fulviventris foraging on the Cassia came from the nests mapped in Fig. 1 is based on the following:

1) Bees observed leaving a plant with full corbiculae always flew in the direction of one of the nests-the T. fuscipennis toward a former Nasuţitermes termite nest $7 \mathrm{~m}$ up in the fork of a Luehea candida tree (Tiliaceae), and the T. fulviventris to an underground nest at the base of a Lysiloma seemanii tree (Leguminosae).

2) There were no intraspecific agonistic encounters as would have been in the case if conspecifics

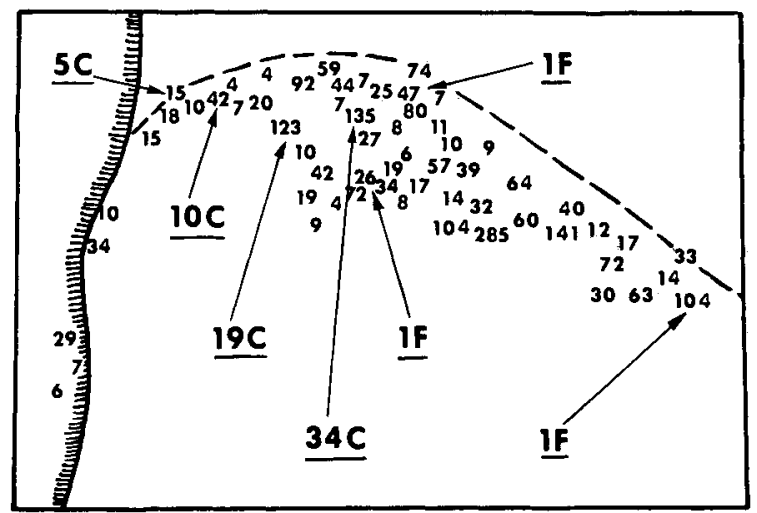

Fig. 2. Far patch insert on study site map of Fig. 1 . Dimensions of area are $60 \mathrm{~m} \times 40 \mathrm{~m}$. Numbers refer to number of flowers on each Cassia plant, and their positions indicate the positions of the plants. Underlined are the number of Trigona fuscipennis (C) or $T$. fulviventris ( $F$ ) visiting the bush indicated by the arrow.

from different colonies had encountered one another (Johnson 1974).

3) The Cassia population was well within the foraging range of the two colonies, but outside or on the fringes of the foraging ranges of the other nearby $T$. fuscipennis and $T$. fulviventris colonies, all of whose locations were known (Johnson 1974).

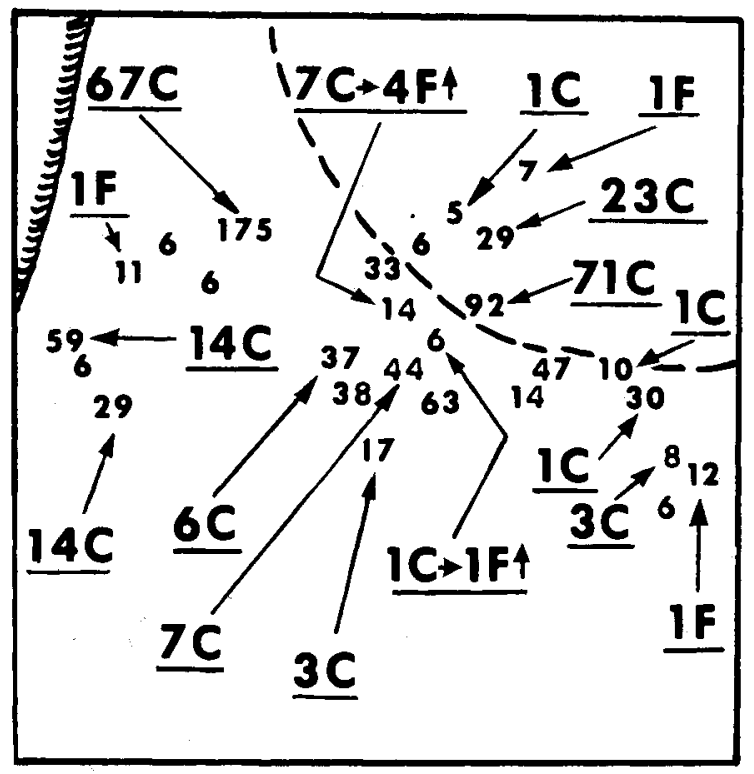

Fig. 3. Near patch insert on the study site map of Fig. 1. The dimensions of this area are $40 \mathrm{~m} \times 40 \mathrm{~m}$. The numbers refer to the number of flowers on each Cassia. Underlining has the same notational meaning as in Fig. 2, with two exceptions. On two bushes Trigona fuscipennis was observed to displace $T$. fulviventris. Thus, the notation $7 \mathrm{C} \rightarrow 4 \mathrm{~F} \uparrow$ indicates that seven $T$. fuscipennis arrived in a group and harassed the four $T$. fulviventris foraging on the bush, causing them to leave. 
What then, were the contrasting foraging patterns of these two colonies on the Cassia population?

Foraging by Trigona fuscipennis

The position of each isolated Cassia bush in the study area is shown in Fig. 1. Not a single $T$. fuscipennis was found on these plants on 18 December or subsequently. The $T$. fuscipennis foraged only on the plants in the near and far patches (Fig. 2 and 3 ), there being no other Cassia clumps within reasonable foraging distance, i.e., less than $300 \mathrm{~m}$. The far patch was approximately twice as far from the nest as the near patch (103 vs. $57 \mathrm{~m}$ ), yet it was visited by less than a third of the total number of $T$. fuscipennis workers foraging on Cassia (Table 1). More than $50 \%$ of the plants in the near patch were visited, whereas less than $10 \%$ were visited in the far patch. The average number of flowers/plant was significantly higher on visited vs. nonvisited bushes, suggesting the bees actively chose those plants within the clump with the most flowers. We found no significant difference between average number of flowers/visited plant in the far vs. near clumps.

Overall, the $T$. fuscipennis were clumped in their distribution on the bushes, i.e., they occurred in groups. The number of $T$. fuscipennis workers visiting a Cassia bush increased with increasing numbers of flowers on the bush (Fig. 4). In the near patch the number of workers increased significantly more steeply with an increase in flower number than was the case in the far patch $(p<0.05)$. In both patches the bees devoted more total attention to plants with more flowers, but the increase is a proportional one, not accelerating. Fitting a curvilinear equation with a quadratic term does not significantly increase the proportion of the variance explained by the regression. A visited plant in the far patch had about $44 \%$ as many bees as a visited plant with an equal number of flowers in the near patch. How the bees originally chose a Cassia bush remains unexplained. Some plants with few flowers were visited by $T$. fuscipennis and some plants with many flowers were not visited by $T$. fuscipennis over the entire 2-wk period of observation (Fig. 2-3). We could discern no difference in quality between the flowers of visited and unvisited plants.

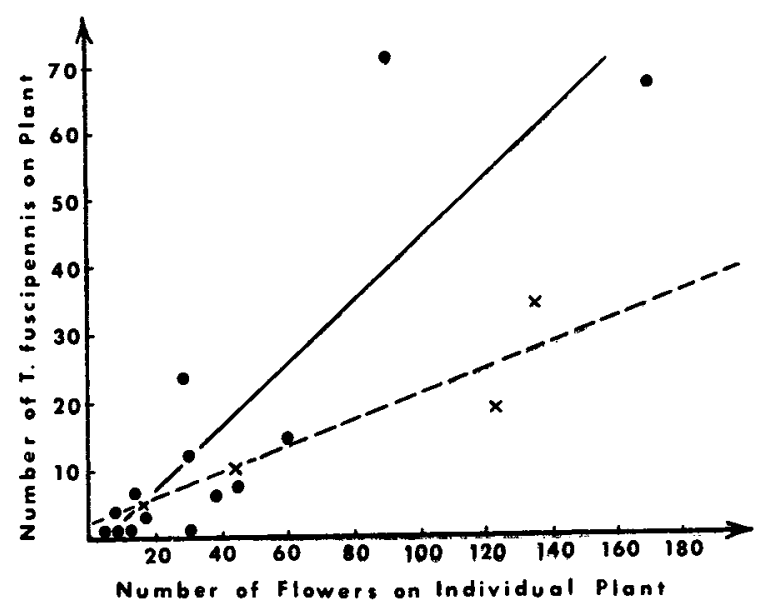

FIG. 4. Graph showing how numbers of Trigona fuscipennis visiting a Cassia bush increases with number of flowers on visited bush. $\mathbf{X}=$ plants in the Far patch; closed circle $=$ plants in the Near patch. Separate least squares regressions have been calculated for the Near and Far Cassia patches. Slopes are significantly different from one another and from zero at the $p=0.5$ level, Lower slope for the Far Cassia patch reflects lower total recruitment of bees to that area relative to the Near patch.

\section{Foraging by Trigona fulviventris}

There was no significant difference between the mean distances of clumped and isolated plants utilized by $T$. fulviventris, yet only $26 \%$ of the $T$, fulviventris workers visiting Cassia went to plants in clumps (Table 2). They tended to visit isolated plants even though plants in clumps averaged more flowers/plant (37.5) than isolated plants (24.7), While there was no significant difference in mean number of flowers/ visited and unvisited isolated plants, plants in clumps visited by $T$. fulviventris had significantly fewer flowers than plants not visited,

These patterns raise the possibility that $T$. fuscipennis, which visited only the plants in clumps, and those with the most flowers, partially excluded T. fulviventris from these plants and from the patches. Evidence for exclusion is twofold. First, no T. fulviventris or Hymenoptera of any kind (except an occasional ant) were ever found on a plant occupied by more than one $T$. fuscipennis. Second, on two bushes in the near clump, $T$. fuscipennis was

Table 1. Summary of Cassia biflora exploitation by Trigona fuscipennts

\begin{tabular}{lccccccccc}
\hline & $\begin{array}{c}\text { Average } \\
\text { nest-plant } \\
\text { distance }(\mathrm{m})\end{array}$ & $\begin{array}{c}\text { No. of } \\
\text { plants }\end{array}$ & $\begin{array}{c}\text { Total } \\
\text { visited }\end{array}$ & $\begin{array}{c}\% \\
\text { visited }\end{array}$ & $\begin{array}{c}\text { Average no. of } \\
\text { flowers/plant }\end{array}$ & Visited & Not visited & $\begin{array}{c}\text { Total no. } \\
\text { of bees }\end{array}$ & Flowers/bee \\
\hline Near patch & 57 & 27 & 14 & 51.9 & 39.6 & $20.6^{* *}$ & 219 & 2.53 \\
Far patch & 103 & 62 & 4 & 6.5 & 78.8 & $38.4^{* * *}$ & 68 & 4.63 \\
\hline
\end{tabular}

${ }^{2}$ Visited plants only. ${ }^{* *} p<0.025$; ${ }^{* *} p<0.001$. 
TABLE 2. Summary of Cassia biflora exploitation by Trigona fulviventris

\begin{tabular}{|c|c|c|c|c|c|c|c|c|}
\hline & \multirow{2}{*}{$\begin{array}{c}\text { Average } \\
\text { nest-plant } \\
\text { distance }(\mathrm{m})\end{array}$} & \multirow{2}{*}{$\begin{array}{l}\text { No. of } \\
\text { plants }\end{array}$} & \multirow{2}{*}{$\begin{array}{c}\text { Total } \\
\text { visited }\end{array}$} & \multirow{2}{*}{$\begin{array}{c}\% \\
\text { visited }\end{array}$} & \multicolumn{2}{|c|}{$\begin{array}{l}\text { Average no. of } \\
\text { flowers/plant }\end{array}$} & \multirow{2}{*}{$\begin{array}{l}\text { Total no. } \\
\text { of bees }\end{array}$} & \multirow[b]{2}{*}{ Flowers/bee } \\
\hline & & & & & Visited & Not visited & & \\
\hline $\begin{array}{c}\text { Clumped } \\
\text { Cassia }\end{array}$ & 92 & 89 & 9 & 10.1 & 26.1 & $38.8 * *$ & 12 & 19.6 \\
\hline $\begin{array}{l}\text { Isolated } \\
\text { Cassia }\end{array}$ & $80 \mathrm{NS}$ & 29 & 12 & 41.4 & 23.2 & $25.7 \mathrm{NS}$ & 35 & 8.0 \\
\hline
\end{tabular}

${ }^{a}$ Visited plants only. $\mathrm{NS}=$ not significant, ${ }^{* *} p<0.05$.

observed in the act of displacing $T$. fulviventris (Fig. 3). In one case seven T. fuscipennis drove off four $T$. fulviventris. One or two $T$. fuscipennis would hover a few millimeters from a pollen-collecting $T$. fulviventris and cause it to fly away. Since two displacements were seen in a total of $3 \mathrm{~h}$ of observation of Cassia in clumps, it is likely such events occurred relatively frequently, at least in the near patch. A low, continual displacement rate might produce the low visitation rate of $T$. fulviventris on clumped Cassia.

\section{Comparison of the patterns}

With regard to the spatial aspects of foraging we found visited plants were farther from the nest for Trigona fulviventris than for $T$. fuscipennis, but the average distance travelled/bee was no different in the two species (Table 3 ). The mean number of bees/visited plant was seven times greater for $T$. fuscipennis, but $T$. fulviventris visited more plants. That $T$. fulviventris consistently visited more isolated plants than $T$. fuscipennis is evident from the figures on mean distance to nearest Cassia from each plant visited by $T$. fuscipennis and $T$. fulviventris. Plants visited by $T$. fulviventris were an average of $8.1 \mathrm{~m}$ from their nearest neighbor, whereas $T$. fuscipennis plants were, on the average, only $1.5 \mathrm{~m}$ from their nearest neighbor; the difference was significant $(p<0.05)$.

Figure 5 emphasizes more dramatically the spatial difference in foraging between the two species. Morisita's Index of Dispersion (Morisita 1959), $I_{\delta}$, was computed for a range of quadrat sizes from $25 \mathrm{~m}^{2}$ to $6,400 \mathrm{~m}^{2}$ for the Cassia population. First it was computed for all Cassia bushes, then only for Cassia visited by $T$. fuscipennis, and finally only for Cassia visited by $T$. fulviventris. As Morisita has pointed out, how the Index of Dispersion, $\mathbf{I}_{\delta}$, changes with increasing quadrat size reveals a great deal about the dispersion pattern on different scales of observation. Thus, in our case, the line marked with a " 2 " for all Cassia plants indicates overall a highly clumped population dispersion with a mean clump size of about $800 \mathrm{~m}^{2}$ and suggests a relatively uniform plant spacing within clumps.

The Cassia subpopulations visited by $T$. fuscipennis and $T$. fulviventris have dispersion patterns distinctly different from the Cassia population as a whole and from each other. The Dispersion Indices for plants visited by $T$. fuscipennis are significantly higher than for all Cassia bushes. This indicates that the $T$. fuscipennis plants are more highly clumped than an equally sized random sample of the population as a whole. In contrast, the $T$. fulviventris plants have lower Indices of Dispersion than Cassia bushes at all quadrat sizes, and hence are more uniformly spaced.

\section{Persistence of the patterns}

These visitation patterns persisted on the 36 Cassia plants selected for periodic observation at various times of day during the next $2 \mathrm{wk}$. Each bee species continued to occupy the same bushes it originally occupied. The rates of visitation were very constant (Table 4). We computed the mean and the variance of the number of bees/plant over the set of observations. The constancy of the number of bee visitors is indicated by the exceptionally low variance-to-

TABLE 3. Comparison of foraging patterns of Trigona fulviventris and T. fuscipennis on Cassia biflora

\begin{tabular}{lcccccc}
\hline & $\begin{array}{c}\text { Average } \\
\text { distance to } \\
\text { visited } \\
\text { plants }(\mathrm{m})\end{array}$ & $\begin{array}{c}\text { Total no. } \\
\text { of bees }\end{array}$ & $\begin{array}{c}\text { Average one- } \\
\text { way distance } \\
\text { traveled/bee } \\
(\mathrm{m})\end{array}$ & $\begin{array}{c}\text { Average no. of } \\
\text { bees/visited } \\
\text { plant }\end{array}$ & $\begin{array}{c}\text { No. of } \\
\text { plants } \\
\text { visited }\end{array}$ & $\begin{array}{c}\text { Average distance } \\
\text { from visited } \\
\text { plant to nearest } \\
\text { neighbor }(\mathrm{m})\end{array}$ \\
\hline $\begin{array}{l}\text { Trigona } \\
\text { fulviventris }\end{array}$ & 85.8 & 47 & 68.0 & 2.2 & 21 & 8.1 \\
$\begin{array}{l}\text { Trigona } \\
\text { fuscipennis }\end{array}$ & $65.5^{* *}$ & 287 & $64.9 \mathrm{NS}$ & $15.0^{* * *}$ & 18 & 1.5 \\
\hline
\end{tabular}

NS $=$ not significant, ${ }^{* *} p<0.05, * * * p<0.001$. 


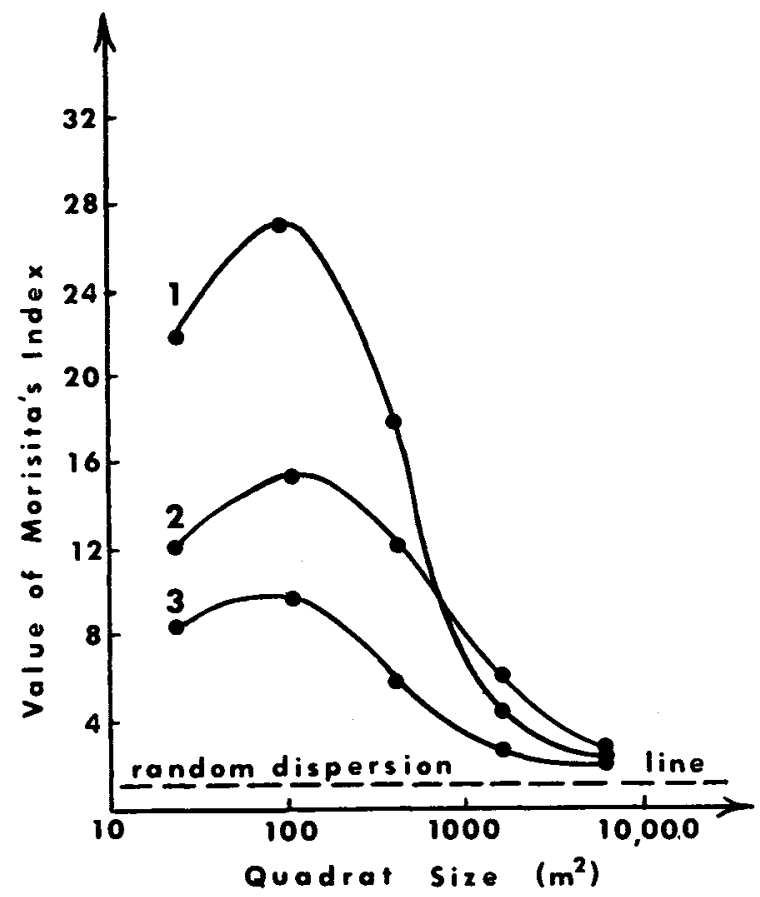

FIG. 5. Clumping in the Cassia biflora population. Morisita's Index of Dispersion calculated for quadrat sizes $25,100,400,1600$ and $6,400 \mathrm{~m}^{2}$. (1) only bushes visited by Trigona fuscipennis, (2) all Cassia bushes, and (3) only bushes visited by $T$. fulviventris. Dotted line is drawn for $I_{\delta}=1.0$.

mean ratio computed for each plant (range: 0.41 $1.50)$. There are no significant differences between average ratios computed for $T$. fuscipennis and $T$. fulviventris plants separately. A low variance-to-mean ratio was also found for bushes not visited by bees in the original observations. In large measure these plants remained unvisited: none was subsequently seen with more than two bees of either species.

We believe the constancy of visitation pattern can be principally attributed to the constancy of individual workers to specific plants. Of five individually marked $T$. fulviventris, four were seen $2,2,4$, and 4 times respectively on the same plant on different days, but not elsewhere. The fifth bee appeared three times on one plant, and a fourth time on a plant only $4.5 \mathrm{~m}$ away. Moreover, the second plant was on a line between the bee's original plant and the nest. The fifth bee was watched continuously between 1200 and 1530 on 28 December. It made two round trip flights to the nest, each time returning to the same plant, where it collected pollen for 85 and $55 \mathrm{~min}$.

\section{Concurrent patterns on Calycophyllum flowers}

Observations in other seasons confirm that Trigona fuscipennis almost invariably forages in groups; we have also observed this species to arrive in a group at a new resource after discovery of the resource by a "scout." Trigona fulviventris on the other hand usually forages in a much more highly dispersed manner (Johnson 1974). These foraging patterns were also observed on Calycophyllum candidissimum, which was the only other major food resource visited by either Trigona species during the study. Trigona fuscipennis visited only the three Calycophyllum trees nearest its nest, at distances of 15,17 , and $24 \mathrm{~m}$ respectively (Fig. 1). A typical branch was covered with an estimated 22 workers $/ \mathrm{m}^{2}$ of branch surface. There were virtually no other bees or wasps on this branch, and the few wasps which did attempt to land were aggressively chased away by $T$. fuscipennis.

In contrast, $T$. fulviventris foraged at relatively low densities (2-4 bees $/ \mathrm{m}^{2}$ ) on 13 Calycophyllum trees which averaged $75.8 \mathrm{~m}$ from the nest. Many other bees and wasps foraged alongside $T$. fulviventris, especially the stingless bees Trigona capitata zexmeniae Cockerell $\left(1.2 / \mathrm{m}^{2}\right), T$. pectoralis Dalla Torre $\left(1.0 / \mathrm{m}^{2}\right)$ and Melipona beecheii Bennett $\left(<1.0 / \mathrm{m}^{2}\right)$.

\section{Discussion}

The results indicate that Trigona fuscipennis forages in groups monopolizing the Cassia plants

TABLE 4. Constancy of bee visitation rates over a 2-week observation period on selected Cassia plants

\begin{tabular}{|c|c|c|c|}
\hline & & $\begin{array}{l}\text { Number of } \\
\text { resurveyed } \\
\text { plants }^{2}\end{array}$ & $\begin{array}{l}\text { Average } \\
s^{2}: \bar{x}\end{array}$ \\
\hline $\begin{array}{l}\text { Plants } \\
\text { categorized } \\
\text { by location }\end{array}$ & $\begin{array}{l}\text { Isolated plants } \\
\text { Near patch } \\
\text { Far patch }\end{array}$ & $\begin{array}{r}11 \\
10 \\
9\end{array}$ & $\begin{array}{l}0.805 \pm 0.274^{*} \\
0.820 \pm 0.301 \\
0.816 \pm 0.119\end{array}$ \\
\hline $\begin{array}{l}\text { Plants } \\
\text { categorized } \\
\text { by visitors }\end{array}$ & $\begin{array}{l}\text { Originally unvisited } \\
\text { Originally } T . \text { fuscipennis } \\
\text { Originally } T . \text { fulviventris }\end{array}$ & $\begin{array}{r}8 \\
10 \\
12\end{array}$ & $\begin{array}{l}0.916 \pm 0.207 \\
0.838 \pm 0.282 \\
0.800 \pm 0.178\end{array}$ \\
\hline Total & & 30 & \\
\hline
\end{tabular}

* Confidence limits for $p=0.05$.

a Plants never visited were excluded from this calculation. 
visited, while $T$. fulviventris forages in lower numbers on more widely dispersed Cassia.

These patterns can be explained by two related hypotheses. First, T. fuscipennis may be an aggressive, group-foraging species that preempts desirable (clumped) food sources, thereby displacing $T$. fulviventris to less desirable (isolated) food sources. The second hypothesis is that the observed group and solitary foraging patterns may be due, not to short term competitive displacement, but to evolved differences in foraging behavior. We shall present evidence for both hypotheses, then suggest that both are correct. Certainly, the second hypothesis is the evolutionary consequence of long-applied competition of the sort proposed by the first hypothesis, so in the final analysis they cannot be mutually exclusive.

First consider evidence for the competition hypothesis in its purest form. Trigona fuscipennis does aggressively displace $T$. fulviventris from Cassia in clumps, and from the nature of the observation, such displacements must be relatively frequent. Also we consistently observed that whenever $T$. fuscipennis occupies a Cassia (or Calycophyllum) no other foraging bees visit that plant. The implication is that, if $T$. fuscipennis is not present, $T$. fulviventris will focus its attention on the Cassia patches instead of visiting widely scattered plants. A direct test of this prediction would be to find a site where $T$. fuscipennis is absent but $T$. fulviventris is present, along with a Cassia population having all the necessary spatial attributes of clumps and isolated plants, and to observe if $T$. fulviventris, in the absence of competition, concentrates its foraging in clumps of Cassia. Unfortunately we did not find such a site. The possibility remains of temporarily closing the $T$. fuscipennis nest (wrapping it in screen) or removing it completely.

There is reason to expect, however, that the removal of $T$. fuscipennis might have little effect on the foraging pattern of $T$. fulviventris, supporting the alternate hypothesis that $T$. fulviventris has a well-evolved foraging strategy. If $T$. fulviventris had chosen to visit the Cassia clumps, there were many unoccupied plants it could have visited. Only $6 \%$ of all plants in the far patch and $48 \%$ of the plants in the near patch were visited by $T$. fuscipennis, leaving many plants, some with a large number of flowers, completely unoccupied. There was no evidence that $T$. fuscipennis was guarding or patrolling these other plants.

On the other hand, T. fuscipennis need not be physically present on a food source to deter $T$. fulviventris temporarily. Trigona fuscipennis frequently marks food sources with pheromone (Johnson 1974, A. Wille, personal communication), a device which aggregates them and helps them locate the food on a subsequent trip. This pheromone may also deter potential competitors, as suggested by a test of the effect of $T$. fuscipennis pheromone on $T$. fulviventris. When honey-water baits were set up at a site to which $T$. fulviventris had been trained, the $T$. fulviventris normally hovered for $2-5 \mathrm{~s}$ a few millimeters from the bait, then landed and fed, and recruited $50-80$ bees in $30 \mathrm{~min}$. When baits recently visited and marked by $T$. fuscipennis were transferred to the site, however, the $T$. fulviventris workers flew around them rapidly, landed briefly without feeding, and did not recruit more than 50 bees until $2 \mathrm{~h}$ had elapsed.

We would expect $T$. fuscipennis and their pheromone droplets to occur together on Cassia plants, since the pheromone has an aggregating function. But the odor of this pheromone might be perceived from nearby bushes in a clump, causing the $T$. fulviventris to shun them and the whole area. Stingless bees, some species of which recruit by means of odor trails (Lindauer and Kerr 1960), can perceive their own pheromone from at least several $m$ (Kerr 1959). Presumably those of other species can be detected from this distance.

The evidence is that $T$. fuscipennis did partially exclude $T$. fulviventris from the Cassia clumps, but that at the same time $T$. fulviventris had a strong behavioral tendency to forage in a spatially dispersed manner, as it did on Calycophyllum and does on many other flower species (Johnson 1974). Parenthetically we note that $T$. fulviventris is capable of recruiting workers to a source, as it did in the bait experiment described above and probably also in the case of isolated Cassia bush No. 5, which had 11 bees and an unusual number of flowers (90) for a $T$. fulviventris bush. The "decision" to forage singly or in small groups is somehow being made. Perhaps the food quality threshold for marking and recruitment is higher for $T$. fulviventris than for $T$. fuscipennis.

If these foraging patterns reflect evolutionary strategies, what are the selective forces which could have shaped them? In an earlier paper (Johnson and Hubbell 1974) we predicted that aggressive species should be large, such as Trigona silvestriana Vachal. Here we add that bees which are medium-sized and forage in groups can also use aggressive techniques in resource competition, and that they should likewise specialize on food resources clumped in space and time. This prediction was borne out for Trigona corvina Cockerell in the earlier study and also for $T$. fuscipennis in the present work. In the above paper we argue that aggressiveness and monopoly of food resources arose out of intense intraspecific competition for food. Our observation of the uniform intraspecific dispersion of $T$. fuscipennis and 
$T$. silvestriana nests in the forest around the study area also supports this conclusion.

We turn now to the question of competition between $T$. fuscipennis and $T$. fulviventris. In this paper we use the term "interspecific competition" in a somewhat different sense than is customary in ecology. Traditionally the term refers to the negative effect of a population of one species on the growth rate and equilibrium size of a population of another species. In our case, we cannot directly assess the long-term numerical consequences of the short-term interactions we have seen. Other things equal, however, the long-term result of exclusion of $T$. fulviventris by $T$. fuscipennis from shared food resources would seem clear: an increase in the number of $T$. fuscipennis colonies at the expense of the number of $T$. fulviventris colonies. The negative effect of competition would be reduced if $T$. fulviventris took an evolutionary escape route, by foraging on isolated plants.

Foraging on widely spaced plants need not be any more costly energetically than foraging on clumped plants provided that the plants flower for long periods. Such plants can be revisited by plantconstant bees with a minimum of search effort once they have been located.

One could argue that the only reason $T$. fulviventris persisted on Cassia at all was because hundreds of $T$. fuscipennis foraged on Calycophyllum, leaving some Cassia bushes unoccupied. We believe, however, that even if a greater number of $T$. fuscipennis had foraged on Cassia, they would not have expanded to visit isolated plants outside the patches. Group foraging appears to be suited for spatially aggregated food resources, which can be effectively guarded by a group of bees against rival colonies. Whereas an isolated bush is also a defensible food source, the food returns/bee, in a group of a size sufficient for defense, would be too low. Of course, this leaves unanswered the question of why $T$. fuscipennis always or nearly always forages in groups, but this is an observed fact. A possible evolutionary explanation is that, over the history of $T$. fuscipennis as a species, clumped, defensible resources have continually and predictably been available.

Trigona fulviventris, whose foraging force tends to be too spread out for effective defense, nevertheless can effectively exploit small, isolated food sources, which do provide ample food for the few workers that forage on them.

In summary, the evidence supports our contention that the observed foraging patterns of these bees result from both evolved strategies and competitive displacement. First, $T$. fuscipennis does seem to forage in groups and avoid isolated plants. In the few cases in which single workers occurred alone on a Cassia, the plant was invariably very close to one or more heavily visited plants. This observation suggests that such bees were not foraging alone but were strays from the heavily visited plants.

Second, T. fuscipennis selected the plants with the most flowers, which provide food for more bees and are more worth defending. The average number of flowers on isolated plants (24.7) is significantly lower than the number on plants which $T$. fuscipennis selected to visit in the clumps (48.3). The average number of flowers on isolated plants falls to 22.3 if one unusually high value of 90 (plant No. 5) is eliminated from the sample. There may be a threshold number of flowers/plant, below which $T$. fuscipennis is unlikely to visit, and very unlikely to mark and recruit. Most isolated plants fall below this threshold if we accept the contention that the few $T$. fuscipennis workers found on plants in clumps with a low flower number are strays from nearby heavily visited ones, and do not represent recruitment to these particular plants. Isolated shrubs commonly do less well and produce fewer flowers than many of the plants growing in clumps, a pattern which helps tip the balance further in favor of the foraging strategy of $T$. fulviventris on isolated plants. We have also seen this pattern of greater flower production per plant in clumps of other tropical dry forest or second growth shrubs, notably Cordia currasavica (Boraginaceae) and $C$. inermis, plants heavily visited by Trigona in the wet season.

Finally, $T$. fulviventris seems to be comparatively quick in finding new resources; it takes $T$. fulviventris much less time than $T$. fuscipennis to discover sugar baits (Johnson 1974). This ability to discover new food resources quickly has been seen many times in $T$. fulviventris in the case of natural resources as well, which could be due in part to the high dispersion of the foraging force.

Thus the observed patterns on Cassia appear to be the result not only of competition in contemporary time, but also of competition in evolutionary time. Evolved behavior patterns lend each species a food resource "refuge" even when the resource is taxonomically identical for both species.

We label as strategies such evolved behavior patterns and we define strategy below. An adaptation is any heritable morphological, physiological or behavioral trait or collection of traits of an organism assembled by natural selection by virtue of the enhanced reproductive success it gave the organism's ancestors. An adaptive syndrome is a collection of heritable traits whose fitness-enhancing action results from their performance in concert rather than from their individual actions alone. The word strategy has been used in evolutionary biology with at least two valid meanings. One meaning of strategy is 


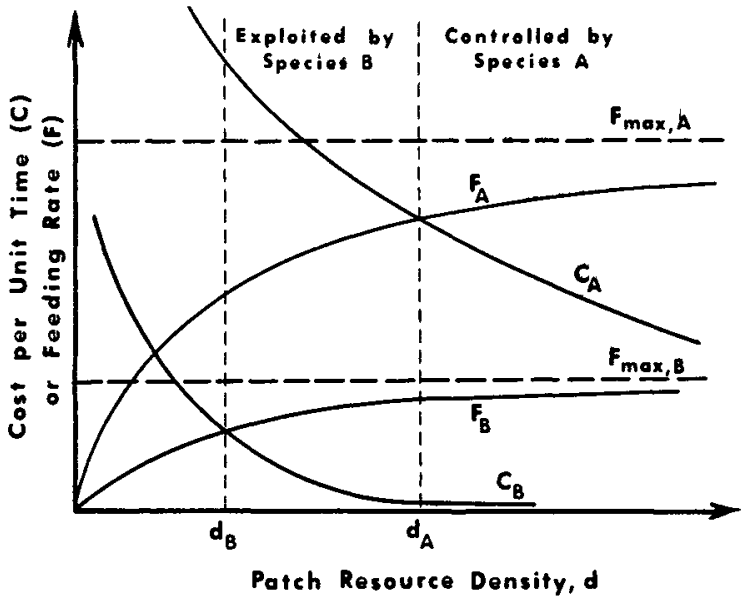

FIg. 6. Hypothetical cost-benefit relationships for a high-density (species A) and a low-density (species B) specialist exploiting a common limiting resource. $F_{\mathrm{A}}$ and $F_{\mathrm{B}}$ are feeding rates; and $C_{\mathrm{A}}$ and $C_{\mathrm{B}}$ the costs of foraging and maintenance per unit time, for species $A$ and $B$ respectively. The resource environment is assumed to be patchy with wide variation in patch resource density. Resource density, $d$, is measured locally from patch to patch.

an adaptive syndrome of an organism which has a flexible phenotypic expression depending upon the environmental appropriateness of each possible phenotype. An example would be a complex, flexible behavior pattern which changes depending upon the organism's synthesis of current environmental conditions. Some authors have used the word tactic to describe these particular phenotypes as expressed in any given environment, as distinct from the overall strategy of deployment of particular tactics. The second meaning is more appropriate to our usage here, in which strategy refers simply to different adaptive syndromes in different species, as detected by the differing responses of the species to the same or similar environments. The first meaning refers to intraspecific phenotypic flexibility that is adaptive; the second meaning may or may not connote adaptive flexibility, but it does connote differences in adaptation between species faced with the same environment.

\section{HYPOTHESIS}

These results suggest to us that a resource with a highly variable local density can be stably partitioned by two species specialized for exploiting at different resource densities. The conditions are that (1) the low density resource is profitably harvested by only one species, (2) the high density resource is controlled by the second species, and (3) there is no net movement through time of resource from dense to sparse regions or vice versa.
We propose that density specialization can evolve when wide spatial variation in limiting resource densities persists over evolutionary time. If, in the evolutionary history of a species, limiting resources tend to be clumped in defensible patches, we might expect a "high-density specialist" to evolve. Species with access to dense patches often have such access only because they can exclude rivals. For solitary animals this ability is often related to large size; in eusocial animals, group aggression becomes a possible competitive mechanism. It is the adaptive syndrome of high-density specialists, however, which makes it unprofitable for them to exploit low-density resources. Large or legion animals have increased maintenance costs and require greater resource density before foraging is profitable.

On the other hand, if, in the evolutionary history of a species, limiting resources tend to occur in small, dispersed parcels, we would expect a "low-density specialist" to develop. A low-density specialist has nothing to gain and much to lose by larger size or group foraging because the amount of resource in each parcel is too small to repay the costs of aggression and large size. Therefore, solitary low-density specialists should be small; eusocial ones should be small and exhibit solitary worker foraging.

Figure 6 graphs the cost-benefit analysis of two hypothetical species. Species $\mathrm{A}$ is a large or groupforaging organism that specializes on high-density resource patches. Species B is smaller or forages alone. Resource density $d$ increases along the $\mathrm{x}$ axis. We assume species $A$ and $B$ to have saturating functional responses to resource density (Holling 1966) of the type given by the saturating chemical kinetic equation:

$$
F(d)=\text { feeding rate }=\left(F_{\max } \cdot d\right) /(K+d)
$$

where $F_{\max }$ is the upper limit on feeding rate at high density, $d$, and $K$ is the value of $d$ at half-saturation, when $F=F_{\max } / 2$.

Because species $\mathrm{A}$ is larger or forages in groups it has a higher potential maximum feeding rate, $F_{\max }$, than species B. However, species A also has higher maintenance costs per unit time. We assume that these costs, $C_{\mathrm{A}}(d)$ and $C_{\mathrm{B}}(d)$, fall with increasing resource density as the added energy necessary for search diminishes (although these costs need not diminish with increasing resource density for the argument to hold). Neither species profitably exploits resources below the densities at which the feeding rate $(F)$ and cost functions $(C)$ cross. We call these critical densities $d_{\mathrm{A}}$ and $d_{\mathrm{B}}$ for species $\mathrm{A}$ and $B$ respectively. A necessary condition for the resource to be stably partitioned is that there exist densities at which $\mathrm{B}$ alone can profitably forage.

This condition is met whenever $d_{\mathrm{B}}<d_{\mathrm{A}}$, which 
is the same as the requirement that $C_{\mathrm{A}}$ still exceed the value of $F$ for species $A$ at the critical resource density of species $\mathrm{B}, d_{\mathrm{B}}: C_{\mathrm{A}}(d)_{d=d_{\mathrm{B}}}>F_{\max , \mathrm{A}} \cdot d_{\mathrm{B}} /$ $K_{\mathrm{A}}+d_{\mathrm{B}}$, whereas $F_{\max , \mathrm{A}}$ is the maximum feeding rate for species $A$, and $K_{A}$ is the half-saturation parameter for species $A$.

A second necessary condition for a stable density partition of a single resource is that there be no mixing of resource between low- and high-density patches. If the resource is well-mixed such that patches of dense and sparse resource are continually created and destroyed from random subsets of the entire resource pool, no stabilization is possible. With random mixing and reallocation, competition occurs for the entire resource pool, and eventually the species with the lowest maintenance cost wins. Thus, if the resource is a highly mobile prey or floats in a well-mixed body of water, we would expect purely exploitative competition as opposed to density specialization and aggressive competition.

An exception to this requirement may occur in the case of organisms which have evolved an escape in space or time. An organism can be high-density specialist on a well-mixed resource only if, when resources fall to low levels, it can emigrate to a location with dense resources or go into a resting state to wait for the return of dense resources. For example, many species of phytoplankton grow and divide only when nutrients are concentrated after spring or fall overturn. When concentrations of limiting nutrients fall to low levels in mid-summer, these species commonly settle out and enter a resting state until the next lake overturn. Alternatively, a small fraction of the population may survive in the water column until the next overturn and act as a founder population. The latter possibility has been examined mathematically by Stewart and Levin (1973), who have shown that stability and coexistence are possible on a single resource in a periodic environment in which resource density seasonally alternates between high and low levels.

Although the preceding discussion has concerned one resource, it should be noted that low- and highdensity specialists can arise more easily when more than one resource is involved. Whether we suppose many exploitable resources, all of which exhibit wide density variations from place to place, or some of which are always dense and others always sparse, the effect of added resources will always be to increase the long-term predictability and stability of at least some resource at each of a variety of densities. Given that these resources are limiting, specialization of exploiting species for different densities seems highly probable.

We believe that coexistence by density specialization will be found to be common among competing terrestrial herbivores or plant-product specialists, especially among generalized flower-visiting insects. The immobility of terrestrial plants means different density patterns remain relatively fixed and, for this reason, constitute separately exploitable resources. Density specialization can be added to the list provided by Haigh and Smith (1972) of situations in which species can outnumber the limiting resources. Alternatively it can be considered a special case of their category called "self-limited predators" if the term "consumer" is substituted for "predator." This self-limitation arises out of behavioral choice constrained by the adaptive syndrome of the species. The constraints result from an evolutionary branching in adaptations induced by long-term differences in patterns of spatial dispersion of limiting resources.

\section{ACKNOWLEDGMENTS}

We thank Roy L. Caldwell, C. H. F. Rowell, and especially Paul Opler and Bernd Heinrich, whose freely given ideas contributed to this work. Amy Kilham provided field assistance, Dr. Alvaro Wille identified the bees, and Mr. David Stewart kindly granted permission to conduct this study on his property. The study was supported by grant GB-33324 from the National Science Foundation to S. Hubbell, and was conducted while L. K. Johnson held a Graduate Fellowship from the National Science Foundation. This paper is part of a thesis submitted by the senior author in partial fulfillment of the requirements for the degree of Doctor of Philosophy from the University of California, Berkeley.

\section{Literature Cited}

Haigh, J., and J. M. Smith. 1972. Can there be more predators than prey? Theor. Pop. Biol. 3:290-299.

Holdridge, L. R. 1967. Life zone ecology. Tropical Science Center, San José, Costa Rica.

Holling, C. S. 1966. The functional response of invertebrate predators to prey density. Mem. Entomol. Soc. Can. 48:1-85.

Johnson, L. K. 1974. The role of agonistic behavior in the foraging strategies of Trigona bees. Ph.D. Thesis. Univ. California, Berkeley.

Johnson, L. K., and S. P. Hubbell. 1974. Aggression and competition among stingless bees: Field studies. Ecology 55:120-127.

Kerr, W. E. 1959. Bionomy of meliponids. IV. Aspects of food gathering and processing in some stingless bees. In Symp. on food gathering behavior of Hymenoptera. Cornell University, Ithaca, New York.

Lindauer, M., and W. E. Kerr. 1960. Communication between the workers of stingless bees. Bee World 41: 29-41, 65-71.

Morisita, M. 1959. Measuring the dispersion of individuals and analysis of the distributional patterns. Mem. Fac. Sci. Kyushu Univ. Ser. E 2:215-235.

Stewart, F. M., and B. R. Levin. 1973. Partitioning of resources and the outcome of interspecific competition: A model and some general considerations. Am. Nat. 107:171-198.

Wille, A. 1963. Behavioral adaptations of bees for pollen collecting from Cassia flowers. Rev. Biol. Trop. 11:205-210. 